\title{
Ensino remoto emergencial em tempos de pandemia: tecendo algumas considerações
}

\author{
Emergency remote teaching in pandemic times: weaking some \\ considerations
}

\author{
Jacks Richard de Paulo \\ Doutor em Educação \\ Universidade Federal de Ouro Preto - UFOP. \\ Mariana, Minas Gerais - Brasil. \\ jacks@ufop.edu.br
}

Stela Maris Mendes Siqueira Araújo Mestre em Sustentabilidade Ambiental Instituto Federal de Minas Gerais - IFMG.

Ribeirão das Neves - Brasil. stela.araujo@ifmg.edu.br

\author{
Priscila Daniele de Oliveira \\ Mestranda em Educação \\ Universidade Federal de Ouro Preto - UFOP. \\ Mariana, Minas Gerais - Brasil. \\ pdoliveira20@gmail.com
}

Resumo: Esta pesquisa tem o objetivo de analisar os discursos de professores diante da experiência vivenciada no ensino remoto emergencial. Os docentes que participaram da pesquisa atuam em instituições públicas de ensino da rede estadual e municipal e na rede particular em uma região situada no interior do estado de Minas Gerais - Brasil. Para tal, efetuou-se uma revisão da literatura acadêmica que trata da temática objeto desta investigação para compreender as peculiaridades que demandam o trabalho docente para promover o processo de ensino e de aprendizagem no ensino remoto emergencial. Além disso, foi realizada entrevista virtual, individual, com o intuito de dialogar com os docentes sobre as experiências vivenciadas e obter informações que possibilitaram a análise apresentada. Os dados da pesquisa revelaram que há discursos comuns e discrepâncias entre os diferentes níveis, redes de ensino e no processo de ensino e de aprendizagem relatados pelos professores.

Palavras-chave: Educação. Ensino. Pandemia COVID-19. Ensino remoto.

\begin{abstract}
This research aims to analyze the speeches of teachers in the face of the experience with remote emergency teaching. The teachers work in public educational institutions of the state and municipal network in a region located in the interior of the state of Minas Gerais - Brazil. To this end, a review was carried out with the academic literature that deals with the investigative theme, to understand the peculiarities that demand the teaching work to promote the teaching and learning process in emergency remote teaching. In addition, a virtual, individual interview was carried out in order to enhance the dialogue with teachers and obtain the data that enabled the analysis presented. The research data revealed that there are common discourses and discrepancies between the different levels and teaching networks and in the pedagogical practice, in the teaching and learning process reported by the teachers.
\end{abstract}

Keywords: Education. Teaching. Pandemic COVID-19. Remote teaching. 
PAULO, Jacks Richard de; ARAÚJO, Stela Maris Mendes Siqueira; OLIVEIRA, Priscila Daniele de. Ensino remoto emergencial em tempos de pandemia: tecendo algumas considerações

\section{Introdução}

O ano de 2020 ganha um destaque que ficará marcado na história, a pandemia do Covid19. Diante dessa situação houve a necessidade do afastamento social para evitar o contágio, o que levou as escolas a suspenderem seus calendários letivos, a maioria a partir do mês de março. A princípio todos ficaram atônitos com a nova realidade sem saber muito o que fazer e como fazer até que em aproximadamente um mês começaram vários estudos com o intuito de analisar a possibilidade de oferecer o ensino de forma remota.

Neste contexto o Conselho Nacional de Educação (CNE) publicou o Parecer no 5/2020 com as diretrizes para orientar escolas de Educação Básica e instituições de ensino superior durante a pandemia do novo coronavírus referente ao afastamento social, os trabalhos passam a ser desenvolvidos remotamente. Apesar das orientações do documento legal, ainda pairam dúvidas sobre a eficácia de tais atividades, principalmente, se podem favorecer ou não o processo de ensino e de aprendizagem. Portanto, a análise dos discursos dos professores da Educação Básica que atuam em diferentes níveis da rede pública de ensino, poderá fornecer "pistas" que possibilitem uma melhor compreensão deste momento além de estabelecer uma análise comparativa entre os discursos apresentados.

Logo, a título de melhor encaminhar a discussão aqui apresentada, tem-se a definição de ensino que de acordo com Passmore (1980, p. 1) "pode ser caracterizado como uma actividade que visa promover a aprendizagem e que é praticada de modo a respeitar a integridade intelectual do aluno e a sua capacidade para julgar de modo independente". Ademais, caracteriza-se por ser um termo sempre pensado em conjunto com a Educação, apesar de serem diferentes, como pontuam Marques e Oliveira (2016, p. 190):

Existe entre ensino e educação uma diferença basilar. Enquanto que o primeiro se refere
principalmente ao ensino de conteúdos e conhecimentos, o segundo possui contornos
mais complexos, que envolvem aprendizagens curriculares, mas também valores e
atitudes, que visam formar melhor o indivíduo na sua totalidade. No sentido mais amplo,
educação vai além do ensinar, envolve a provisão de possibilidades de autoconhecimento
e valores éticos.

A partir disso, pode-se inferir que o ato de ensinar caracteriza-se por constituir uma troca entre professor e alunos. Assim, baseia-se em um processo que inclui utilização e adaptação de novos métodos, reflexão da prática docente, da necessidade do alunado em questão, interação e diálogo. Nessa perspectiva, nas proposições de Tabile e Jacometo (2017, p. 79), “a construção de conhecimentos em sala de aula deve se constituir de forma gradativa".

A esta ideia, atrela-se o desenvolvimento acelerado das tecnologias, que possibilitam uma maior difusão de conhecimentos. De acordo com Marques e Oliveira (2016, p. 204): 
Hoje, as tecnologias e a Internet colocam ao nosso alcance uma gama infinita de informações e conhecimentos, praticamente em qualquer parte e a qualquer hora, o que representa a grande novidade educacional do início do milênio.

Porém, é sempre viável colocar que todo este potencial benéfico das tecnologias ainda não chegou para todos os estudantes e não impactou plenamente o ensino em todo o país. Outro aspecto é que a velocidade da tecnologia impossibilita os sistemas educacionais de acompanharem esse ritmo de inovação, além do fato de que existem também, por parte de alguns professores, certas resistências quanto ao uso das tecnologias.

Ao pensar em ensino e uso de tecnologias, Marques e Oliveira (2016, p. 204) indicam que diversos termos se fazem presentes, "que são consequência direta das tecnologias aplicadas à educação, como “educação à distância", "aprendizagem à distância” e "ensino à distância"”.

Na medida em que a situação atual delegou a inserção do ensino emergencial, cabe destacar que seu contexto soa diferente da modalidade Educação a Distância, o que significa que não são sinônimos. Este segundo já existe e em sua definição no Art. 80 da LDB:

A Educação a Distância é a modalidade educacional na qual a mediação didáticopedagógica nos processos de ensino e aprendizagem ocorre com a utilização de meios e tecnologias de informação e comunicação, com estudantes e professores desenvolvendo atividades educativas em lugares ou tempos diversos. Decreto 5.622, de 19.12.2005, que regulamenta o Art. 80 da Lei 9.394/96 (LDB).

E o termo "remoto" por sua vez, conforme o Dicionário Online de Português está relacionado a algo que se se encontra longe no tempo ou no espaço. Logo, essa forma de ensino foi imposta porque os professores e alunos estão impedidos de darem continuidade às aulas presenciais. $\mathrm{O}$ fato de se tratar de um caráter emergencial, fez com que rapidamente o planejamento pedagógico para o ano letivo de 2020 fosse substituído dando lugar a atividades pedagógicas mediadas pela internet, cartilhas e programas de televisão. Tudo isso foi providenciado na tentativa de minimizar os impactos da pandemia na aprendizagem. Concordam com isso Moreira et al. (2020, p. 352):

Com efeito, a suspensão das atividades letivas presenciais, por todo o mundo, gerou a obrigatoriedade dos professores e estudantes migrarem para a realidade online, transferindo e transpondo metodologias e práticas pedagógicas típicas dos territórios físicos de aprendizagem, naquilo que tem sido designado por ensino remoto de emergência.

Além disso, ainda completam que:

E na realidade, essa foi uma fase importante de transição em que os professores se transformaram em youtubers gravando vídeo-aulas e aprenderam a utilizar sistemas de videoconferência, como o Skype, o Google Hangout ou o Zoom e plataformas de aprendizagem, como o Moodle, o Microsoft Teams ou o Google Classroom. 
Sabe-se que o momento atual não dispõe de uma totalidade de profissionais experientes. A maioria, dentro deste processo é inexperiente e todas estas tecnologias são utilizadas como um viés instrumental e de testes. Ademais, é de amplo conhecimento da maioria da população do país que as infraestruturas das escolas públicas estão precárias, per além de saber que o currículo da maior parte das instituições não foi pensado para ser aplicado remotamente, o que torna a situação mais complexa. Mesmo assim o CNE (Conselho Nacional de Educação) se articula para regulamentar esse retorno de forma remota e em nota, o portal MEC coloca que:

Para pensar em soluções eficientes, evitar aumento das desigualdades, da evasão e da
repetência, o Conselho recomenda que as atividades sejam ofertadas, desde a educação
infantil, para que as famílias e os estudantes não percam o contato com a escola e não
tenham retrocessos no seu desenvolvimento. "Estamos fazendo todos os esforços no
sentido de dar boas soluções ou mitigações às aflições que estão na ponta, das aflições
das redes de ensino dos estados e dos municípios", disse a secretária de Educação Básica,
Ilona Becskeházy (Portal MEC, 2020).

Este mesmo Portal da Educação MEC, traz as regulamentações para cada nível de ensino, desde a Educação infantil até o ensino Superior, da Educação especial, EJA (Educação de Jovens e Adultos) e da Educação quilombola e indígena. Conforme as regulamentações:

Educação infantil - A orientação para creche e pré-escola é que os gestores busquem uma aproximação virtual dos professores com as famílias, de modo a estreitar vínculos e fazer sugestões de atividades às crianças e aos pais e responsáveis. As soluções propostas pelas escolas e redes de ensino devem considerar que as crianças pequenas aprendem e se desenvolvem brincando prioritariamente (Portal MEC, 2020).

Sobre os anos iniciais do Ensino fundamental:

Ensino fundamental anos iniciais - Sugere-se que as redes de ensino e escolas orientem as famílias com roteiros práticos e estruturados para acompanharem a resolução de atividades pelas crianças. No entanto, as soluções propostas pelas redes não devem pressupor que os "mediadores familiares" substituam a atividade do professor. As atividades não presenciais propostas devem delimitar o papel dos adultos que convivem com os alunos em casa e orientá-los a organizar uma rotina diária (Portal MEC, 2020).

E depois, sobre o Ensino médio:

Ensino fundamental anos finais e ensino médio - A supervisão de um adulto para realização de atividades pode ser feita por meio de orientações e acompanhamentos com o apoio de planejamentos, metas, horários de estudo presencial ou on-line, já que nesta etapa há mais autonomia por parte dos estudantes. Neste caso, a orientação é que as atividades pedagógicas não presenciais tenham mais espaço. Entre as sugestões de atividades, está a distribuição de vídeos educativos (Portal MEC, 2020).

Percebe-se que todas essas orientações e todo tipo de movimentação em prol de amortecer os impactos da pandemia no ensino, são fundamentais para este momento. Porém, quando se expande o olhar para todos os envolvidos, nota-se que todo esse plano para o retorno das aulas não inclui o professor inteiramente, apenas as tarefas que ele exerce. 
É notável que o atual momento consiga unir a sociedade por uma grande semelhança, a de que estão igualmente ameaçados pelo vírus do Covid-19 e por outro lado, distancia-la fisicamente, ante os riscos da doença e das suas consequências. O receio do retorno presencial das aulas e a preocupação quanto à possibilidade de perda do ano letivo, a ausência de uma vacina, insuficiência de informações sobre o Covid-19 e a sua alta taxa de contágio, geraram a necessidade do ensino remoto emergencial. Tal ensino segue como uma opção razoável para a ocasião, mas não está isento de inúmeras tribulações, dentre as quais, a falta de aparelhos e boa conexão por parte de vários alunos e professores, ansiedade, acúmulo de trabalho, evasão, entre outros.

Diante das considerações anteriores e da necessidade de melhor compreender a realidade que permeia esse momento de pandemia, o objetivo principal desta investigação foi o de analisar os discursos acerca do ensino remoto emergencial de professores que atuam na Educação Básica em uma região do interior de Minas Gerais. A pesquisa desenvolveu-se com cunho eminentemente qualitativo, buscando-se refletir sobre os desdobramentos do desenvolvimento do ensino remoto emergencial. Para alcançar os objetivos desta pesquisa, inicialmente, realizou-se uma revisão da literatura acadêmica que trata dos desafios e dos processos de construção do conhecimento em tempos de pandemia do Covid-19.

Em seguida desenvolveu-se a etapa de entrevista virtual com nove (9) professores da Educação Básica, para cuja realização utilizou-se o Google Meet por ser uma plataforma que permite reuniões virtuais. Para o momento dos encontros virtuais, que foram realizados individualmente com cada participante da pesquisa, utilizou-se um questionário semiestruturado que norteou a entrevista e favoreceu a obtenção de informações mais precisas para análise. De acordo com as proposições de Gil (1999), os questionários semiestruturados possibilitam inúmeras reflexões sobre diferentes aspectos, em destaque, no campo educacional, onde tem contribuído por meio de desenho de perguntas que podem ser construídas enquanto possibilidade de conhecer e captar diversas informações que permeiam os processos de ensino e de aprendizagem.

Diante dessa situação ainda pouco conhecida, que acaba por gerar "tensão" nos professores, alunos e suas famílias e toda a comunidade escolar, cabem várias perguntas, dentre elas: Quais as características comuns e discrepantes no Ensino Remoto Emergencial em diferentes redes de ensino?

\section{Categorias de análise}

Os resultados serão apresentados considerando as seguintes categorias de análise: redes de ensino (pública municipal, estadual ou privada), níveis de ensino (Educação infantil, Fundamental 
I, Fundamental II e Ensino médio) e práticas docentes, com o intuito de comparar as semelhanças e diferenças a partir da fala dos professores entrevistados. Com o intuito de tornar o instrumento de pesquisa mais adequado eticamente e menos invasivo à privacidade do indivíduo, criou-se uma tabela para organizar os entrevistados conforme a ordem das entrevistas. Assim, foram identificados em ordem numérica os recortes que atendem aos objetivos desta pesquisa.

\subsection{Redes de ensino: da estrutura de suporte à adesão ao ensino remoto emergencial}

As redes de ensino se dividiram em 07 escolas pertencentes à rede pública municipal, 02 escolas da rede pública estadual e 01 da rede privada. Nisso, cabe destacar que o total de professores participantes foram 09, mas, obteve-se um relato duplo, pelo fato de uma participante atuar em duas redes de ensino diferentes.

Os professores participantes fazem parte de escolas distribuídas em quatro municípios no interior de Minas Gerais. A partir disso, percebeu-se várias diferenças envolvidas neste processo de adesão e condução do Ensino Remoto Emergencial. Assim, a maioria das escolas públicas municipais e estaduais demoraram mais tempo para iniciarem as atividades remotas. Primeiro passaram por períodos de organização dos blocos de atividades, recebimento e distribuição dos cadernos pedagógicos.

Diante deste aspecto, nota-se uma grande discrepância entre as redes públicas e a rede privada, uma vez que a segunda iniciou suas atividades remotas uma semana após o governo instituir a regra do isolamento social.

Dentro desse processo de adesão ao Ensino Remoto Emergencial, percebeu-se também posturas diferentes para condução tendo em vista que algumas secretarias liberaram o uso do Google Meet, Whatsapp, Facebook, entre outras ferramentas de comunicação para envio de vídeos, uso de email, tudo para tentar facilitar as aulas. Mas por outro lado, houve relato de secretaria que limitou o contato do professor com os alunos, optou apenas por receber as atividades dos profissionais e repassar aos alunos através de alguma ferramenta adotada. Vale ressaltar que as escolas públicas, tanto estaduais quanto municipais, não utilizam nenhuma plataforma ou ambiente virtual de aprendizagem, o que reforça a exclusão social conforme afirmam em suas pesquisas (SORJ, 2003; NEY, 2006; SOUZA; PONCIANO, 2010) que os determinantes da exclusão social estão presentes também na exclusão digital. Por exemplo, o acesso à internet tem uma relação diretamente proporcional aos níveis de educação e renda.

Outra configuração importante é o oferecimento de curso de capacitação para os professores, assim como o fornecimento de equipamento eletrônico necessário. Percebeu-se que a 
maioria dos professores, da rede pública atua com base em conhecimentos e equipamentos que já possuíam. Conforme (Silva, 2011, p. 02) "é correto afirmar que o processo comunicacional está tão alicerçado na aula presencial e seus métodos que muitos professores avaliam com certa descrença a utilização de tecnologia da informação e comunicação (TIC)", o que acaba se constituindo em um impasse para se elaborar um conteúdo melhor estruturado tecnologicamente.

Apenas a escola da rede privada investe em capacitação para os professores se especializarem nas ferramentas adotadas. Existem grandes diferenças no processo de ensino e de aprendizagem em todos os níveis de ensino, em todas as redes de ensino, nas práticas dos docentes e no Ensino Remoto Emergencial isso não é diferente.

\subsection{Niveis de ensino: da organização para atender as demandas}

Quanto aos aspectos que os unem, quais sejam as semelhanças, todos os professores participantes da pesquisa concordam que a adoção do Ensino Remoto Emergencial se faz necessária para evitar um distanciamento exagerado entre os alunos e a escola, julgando a falta de contato como prejudicial para a aprendizagem, mesmo sob as condições de alguns problemas relatados, como por exemplo, a falta de acesso por todos os alunos. Além disso, outro aspecto observado em todas as falas foi o amplo uso do aplicativo Whatsapp, que ganhou um destaque como uma boa ferramenta de comunicação neste processo.

Em relação aos níveis de ensino, os docentes que participaram das entrevistas atuam no Ensino Básico: Educação Infantil, Fundamental I e II e Ensino Médio, sendo a maioria na Educação Infantil. Diante dos relatos ficou evidente que em todos os níveis de ensino os professores consideraram o Ensino Remoto Emergencial necessário para o momento, mas que trazem perdas em alguns aspectos. Apenas um professor considerou desnecessário, "uma farsa”, afirmando que: "só tem atividade para o professor e alego que para recebermos os pagamentos é viável que façamos as atividades. O foco é a carga horária do professor". Aqueles que consideram o Ensino Remoto Emergencial necessário apontaram que possibilita de certa forma um "contato" dos alunos com a escola, “[...] apesar da diversificação das ações voltadas à democratização do acesso e à inclusão, as desigualdades fracionam-se, multiplicam-se e diversificam-se no âmbito da escola", conforme relato:

Professor 03- "não é o ideal, faz o que consegue. Para este momento está sendo bom para manter o contato com a escola".

Professor 05- "além da manutenção do vínculo, há a manutenção dos hábitos de escolarização, de certa forma há continuidade do aprendizado".

Professor 08- "é necessário, pois os contatos com as crianças são muito importantes, não se pode abandonar as crianças". 
Em relação à dificuldade para realizar as atividades os professores que atuam na Educação Infantil relataram que todas as atividades desenvolvidas precisam ser orientadas e acompanhadas por um adulto. De acordo com JESUS e GERMANO (2013) é imprescindível a participação do adulto como mediador no processo de aprendizagem, compreender a função do professor e da família na Educação Infantil. Porém, às vezes, o nível de instrução dos pais, compromete a aprendizagem, muitos pais não têm disponibilidade e não podem acompanhar as atividades dos filhos, inclusive na rede privada. Observa-se que:

\footnotetext{
Professor 02- "os pais pediram que as atividades fossem feitas apenas em um horário e que não fosse dado nada além para fazer fora da aula".

Professor 03- "a educação infantil obrigatoriamente precisa do acompanhamento de um adulto".

Professor 04- "Para realizar as atividades as crianças são totalmente dependentes dos pais".

Supõe-se que o incentivo ao envolvimento parental, quando realizado sem considerar as dificuldades que subjazem à tarefa escolar, pode estar omitindo, entre outros elementos, a própria dificuldade da escola em garantir o seu papel, em relação tanto às questões de ensino e de aprendizagem quanto aos aspectos que envolvem o desenvolvimento do indivíduo, como aqueles relacionados à autonomia, à proatividade e à autorregulação do aluno (Fernandez, et al., 2014, p. 535).
}

Os alunos do Ensino Fundamental II e do Ensino Médio não precisam de acompanhamento de um adulto para realização das atividades, mas precisam ser motivados a participar.

Professor 01- "na educação infantil, não é possível, os alunos dependem do professor e tenho dificuldade de orientar as crianças a distância".

Professor 04- "presença mais efetiva dos pais com as crianças, eles ficam mais próximos".

\subsection{Prática docente: o professor dentro deste processo}

As estratégias de tentar manter os alunos em contato com a escola e com uma rotina básica de estudos, não tem sido tarefa fácil. Pôde-se perceber que vários caminhos estão sendo utilizados para contribuir com a aprendizagem. Um exemplo são os cadernos pedagógicos, que constituem um material disponibilizado pelo Estado ou Município com a distribuição avisada por mensagens de Whatsapp ou Facebook. Daí os pais ou alunos retiram o material na escola, assinam um documento para salvaguardar esta ação e contam com uma data limite para efetuar a devolução dos cadernos pedagógicos resolvidos.

Notou-se que a maioria dos professores da rede pública, enviam áudios explicativos e dispõem de momentos para tirar dúvidas dos exercícios, via grupo de Whatsapp, e-mail e até ligações. "O contato com os estudantes na internet ajuda o professor a conhecê-los melhor" 
(Oliveira e Mercado, 2013, p. 02). E ainda, conforme os mesmos autores, “As redes sociais são definidas como um espaço de comunicação síncrona e assíncrona que medeiam a aprendizagem e o desenvolvimento de condições, estratégias e intervenções de aprendizagem num espaço virtual na internet [...]” (Oliveira e Mercado, 2013, p. 02).

Além disso, há diferenças quanto aos momentos destinados para este contato, como mostram os recortes abaixo:

\begin{abstract}
Professor 08- "Sei da dificuldade, então eu atendo aluno ou pai a qualquer momento, me ligam até a noite, às vezes e eu atendo, porque este é o meu trabalho”.

Professor 09- "Existem horários certos para enviar atividades e para tirar dúvidas. A secretaria colocou essa regra. Mas se algum professor quiser passar o número de telefone para os alunos, é opção dele".
\end{abstract}

Em comparação com a rede privada, obteve-se o seguinte relato:

Professor 07- "Pelo fato de muitos pais trabalharem fora ou em home office, me foi solicitado reservar uma hora após as aulas para estar ensinando os alunos fazerem as tarefas. Aí, projeto a página do livro e resolvemos de forma on-line”.

Alguns professores enviam vídeos ou textos complementares, para melhor elucidar as temáticas abordadas nos cadernos pedagógicos que são distribuídos. Para Souza (2007), ao fazer uso de diferentes recursos o professor pode tanto ampliar as possibilidades de ensino quanto de aprendizagem, pois:

\footnotetext{
Utilizar recursos didáticos no processo de ensino e de aprendizagem é importante para que o aluno assimile o conteúdo trabalhado, desenvolvendo sua criatividade, coordenação motora e habilidade de manusear objetos diversos que poderão ser utilizados pelo professor na aplicação de suas aulas (Souza, 2007, p. 112).
}

Além deste material complementar mencionado anteriormente, alguns professores fazem uso de livros digitais, sites e atividades de movimento, como por exemplo:

\footnotetext{
Professor 05- "outro dia pedi aos alunos uma atividade para que fingissem ser repórter e me contassem alguma notícia de casa, por vídeo. E eles incorporaram muito bem a atividade, soube de muitas notícias legais, como nascimento de parentes".

Professor 08- "é possível utilizar vários instrumentos, por exemplo, livro digital e tenho facilidade de utilizar os instrumentos tecnológicos".

Professor 09- "Gosto muito do site Lítera, então, indico para eles".

Professor 09- "O primeiro caderno, achei ele ruim, porque era apenas uma série de questões sem nenhuma explicação e contexto para ajudar os alunos”.
}

O controle de frequência nas redes públicas atrela-se às devolutivas dos alunos através dos cadernos pedagógicos e aos envios de fotos das atividades prontas, embora não se tenha certeza de que os alunos estejam participando de fato. Já na rede privada, como a turma é menor e todos tem acesso à internet, consegue-se um alcance maior. As instituições de ensino precisam dar suporte para viabilizar o ensino e a aprendizagem de forma mais consolidada, tal como aponta 
Saviani (2008, p. 18) “é necessário viabilizar as condições de transmissão e assimilação". Um exemplo é o relato abaixo:

Professor 09- “Os alunos entregarão todos os cadernos pedagógicos prontos só no ano que vem, então fica difícil saber se eles estão fazendo todas as atividades”.

Outro aspecto importante é que alguns professores fazem contato com os alunos que demostram que não estão participando, por meio de ligações ou por mensagens no Whatsapp. Sobre as avaliações, as redes públicas não estão realizando e a rede privada, continua, porém de forma online. Para Silva (2017), vários aspectos precisam ser contemplados em termos da avaliação, pois:

A avaliação da aprendizagem deve ser orientada por instrumentos variados; a coerência não pode ser esquecida, pois deve ser consistente com os objetivos e metodologias e atividades do currículo escolar, considerando os aspectos cognitivos, afetivos e sociais, assumindo características escritas ou orais (Silva, 2017, p. 1).

Em consonância com os preceitos anteriores, destacam-se os recortes abaixo:

Professor 05- "avaliação? não é tempo disso. Precisamos ser mais humanos”.

Professor 07- "as avaliações estão ocorrendo. Os pais buscam os pacotes de avaliação na escola e no dia da prova, todos os alunos precisam participar com a câmera e o áudio ligado".

Neste processo, percebe-se que os retornos para além das atividades enviadas vêm apenas dos alunos da Educação Básica, os quais enviam áudios ou pedem aos pais para ligar para os professores para dizer que estão com saudades e que querem voltar às aulas com os colegas.

De acordo com Estevão (2012), quando a participação da família é ativa o aluno melhora no rendimento escolar, de ruim passa para bom tornando-se mais participativo e motivado. Sabese que é de suma importância o envolvimento da família nos ritos da escola e que tal ação pode impactar a prática docente. Acredita-se que a aproximação com os pais, que não é exclusivamente do(a) professor(a), mas de todo corpo de profissionais da escola, é muito importante em um momento de ensino emergencial.

Ainda, nas proposições de Estevão (2012):

Dentro dessa conjuntura está a família e a escola, a família deve se esforçar em estar presente em todos os momentos da vida de seus filhos, presença que implica envolvimento, comprometimento e colaboração, deve atentar para as dificuldades, não só cognitivas, mas também comportamentais (ESTEVÃO, 2012, pág. 4).

\section{Considerações finais}

Conclui-se que a ideia de se pesquisar e estudar um tema extremamente atual atrelado à área da Educação, se faz pertinente e mais ainda, possibilita um leque bastante vasto de 
PAULO, Jacks Richard de; ARAÚJO, Stela Maris Mendes Siqueira; OLIVEIRA, Priscila Daniele de. Ensino remoto emergencial em tempos de pandemia: tecendo algumas considerações

questionamentos que dizem respeito a este assunto. O esforço que se empreendeu foi o de explorar os discursos de alguns professores que atuam na Educação Básica nos diversos níveis, frente ao Ensino Remoto Emergencial.

Observou-se algumas dificuldades para conseguir um número considerável de profissionais para realizar as entrevistas. Além disso, contou-se com alguns poucos problemas de falhas nas conexões durante as entrevistas realizadas de forma on-line. Mas, é fato que a experiência propiciada por esta pesquisa marca, de forma fundamental, a atuação profissional de todos os envolvidos, pois reforçou a ideia da necessidade permanente de pensar as práticas pedagógicas, visando sempre (re)significar o espaço escolar.

Para além dos relatos mencionados no decorrer do trabalho, notou-se outros aspectos que se faz necessário mencionar, um deles é o fato do cansaço que tem atingido o professor neste momento, as dificuldades para a atuação da maioria dos professores no sentido de se desdobrarem para se adaptar ao Ensino Remoto Emergencial e também, a saudade de retornar ao espaço escolar de forma segura e renovada.

\section{Referências}

BRASIL. Decreto de lei $N^{o} 9.394$, de 20 de dezembro de 1996. Disponível em:http://portal.mec.gov.br/sesu/arquivos/pdf/lei9394.pdf. Acesso em: 02/09/2020.

BRASIL. Ministério da Educação. Conselho Nacional da Educação. Diretriz̧es para escolas durante a pandemia. Disponível em:<http://portal.mec.gov.br/busca-geral/12-noticias/acoes-programas-eprojetos-637152388/89051-cne-aprova-diretrizes-para-escolas-durante-a-pandemia $>$. Acesso em: $02 / 09 / 2020$.

DICIONÁRIO ONLINE DE PORTUGUÊS. Significado do termo Remoto. Disponível em https://www.dicio.com.br/remoto/. Acesso em: 02/09/2020.

ESTEVÃO, E. A. dos S. A importância da participação familiar no rendimento escolar da criança. 2012. Disponível em http:/ / www.scielo.br/scielo.php?script=sci_arttext\&pid=\$1413855720030002000 07\&ng=pt\&nrm=iso. Acesso em de 29/09/2020.

FAGUNDES, Léa, Revista Nova Escola, ano 1999.

FERNANDEZ, Ana Patrícia de Oliveira; PONTES, Fernando Augusto Ramos; SILVA, Simone Souza Costa e; LIMA, Mayara Barbosa Sindeaux; SANTOS, Cláudia Oliveira dos. Envolvimento parental na tarefa escolar. Revista Quadrimestral da Associação Brasileira de Psicologia Escolar e Educacional, SP. Volume 18, Número 3, Setembro/Dezembro de 2014: 529-536. Disponível em:

https://www.scielo.br/pdf/pee/v18n3/1413-8557-pee-18-03-0529.pdf. Acesso em: 27/09/2020.

GIL, A. C. Métodos e técnicas de pesquisa social. 5.ed. São Paulo: Atlas, 1999. 


\section{Dialogia}

PAULO, Jacks Richard de; ARAÚJO, Stela Maris Mendes Siqueira; OLIVEIRA, Priscila Daniele de. Ensino remoto emergencial em tempos de pandemia: tecendo algumas considerações

JESUS, Degiane A. D. de e GERMANO, Jéssica. A importância do planejamento e da rotina na educação infantil. Docência na educação superior: caminhos para uma práxis transformadora. Londrina, 2013. Disponível em: encurtador.com.br/vyAK1. Acesso em: 16 de setembro de 2020.

MARQUES, S.; OLIVEIRA, T. Educação, ensino e docência: reflexões e perspectivas. Revista Reflexão e Ação, Santa Cruz do Sul, v. 24, n. 3, p.189-211, Set./Dez. 2016. Disponível em:http://online.unisc.br/seer/index.php/reflex/index Acesso em: 08/09/2020.

MOREIRA, José António Marques; HENRIQUES, Susana; BARROS, Daniela. Transitando de um ensino remoto emergencial para uma educação digital em rede, em tempos de pandemia. Revista Dialogia. São Paulo, $\mathrm{n}^{\circ} 34$, p.351-364, jan/abr. 351- 363. 2020. Disponível em:

https://www.researchgate.net/publication/341885804_Transitando_de_um_ensino_remoto_emergenc ial_para_uma_educacao_digital_em_rede_em_tempos_de_pandemia Acesso em: 08/09/2020.

OLIVEIRA, Carloney Alves de; MERCADO, Luis Paulo Leopoldo. As redes sociais como espaço de comunicação e interação entre professor e alunos na educação superior. Setor Educacional: Educação Superior. Maceió- AL, 2013, 10 p.

PASSMORE, John. The Philosophy of Teaching. London: Duckworth, 1980, 18p.

SAVIANI, Dermeval. Pedagogia histórico-crítica: primeiras aproximações. 10. ed. rev. Campinas: Autores Associados, 2008. (Educação contemporânea).

SILVA, Patrícia Rodrigues. A importância da capacitação do professor na apresentação das tele aulas e utilização da produção audiovisual em EAD. Campo Grande, abril 2011, 9p.

SILVA, Rebecca Faria. Avaliação escolar como prática mediadora. Revista Educação Pública. ISSN: 1984-6290. Disponível em: <https://educacaopublica.cecierj.edu.br/artigos/17/11/avaliao-escolar-como-prticamediadora> Acesso em: 23/09/2020.1984-6290.

SOUZA, S. E. O uso de recursos didáticos no ensino escolar. In: I Encontro de Pesquisa em Educação, IV Jornada de Prática de Ensino, XIII Semana De Pedagogia da UEM: "Infância e Praticas Educativas", Anais... Maringá: UEM, 2007.

Recebido em: 30 set. 2020/ Aprovado em: 10 nov. 2020

Cite como

(ABNT NBR 6023:2018)

PAULO, Jacks Richard de; ARAÚJO, Stela Maris Mendes Siqueira; OLIVEIRA, Priscila Daniele de. Ensino remoto emergencial em tempos de pandemia: tecendo algumas consideraçõe. Dialogia, São Paulo, n. 36, p. 193-204, set./dez. 2020. Disponível em: https://doi.org/10.5585/dialogia.n36.18318.

\section{American Psychological Association (APA)}

Paulo, J. R., Araújo, S. M. M. S., \& Oliveira, P. D. (2020, set./dez.). Ensino remoto emergencial em tempos de pandemia: tecendo algumas considerações. Dialogia, São Paulo, 36, p. 193-204. https://doi.org/10.5585/dialogia.n36.18318. 